\title{
Intestinal parasitic infections and its association with undernutrition and CD4 T cell levels among HIV/AIDS patients on HAART in Butajira, Ethiopia
}

Dereje Gedle ${ }^{1 *}$, Gemechu Kumera$^{1}$, Tewodros Eshete ${ }^{1}$, Kasahun Ketema$^{1}$, Haweni Adugna ${ }^{2}$ and Fetuma Feyera ${ }^{3}$

\begin{abstract}
Background: Intestinal parasitic infections and HIV/AIDS have been the major public health problems and remain a vital cause of morbidity and mortality in developing countries. Both problems are linked in a vicious cycle. The magnitude of intestinal parasites was prevalent among people living with HIV/AIDS even in the HAART era. However, the pertinent risk factors associated with intestinal parasites among HIV/AIDS patients were not well investigated in Ethiopia particularly at Butajira town. Therefore, the aim of this study was to determine the prevalence of intestinal parasites and associated risk factors among HIV/AIDS patients on HAART in Butajira, Ethiopia.
\end{abstract}

Method: A cross-sectional study was conducted, and a total of 323 study subjects was involved in the study. A systematic random sampling technique was used to select each participant during data collection. Stool specimen was collected and processed using direct wet mount, formol-ether concentration technique, and modified Ziehl-Neelson staining techniques to identify both common and opportunistic intestinal parasites. Structured questionnaire was used to collect socio-demographic, environmental, clinical, and nutritional data. Both bivariate and multivariate logistic regression analyses were used to assess the association of various explanatory factors on intestinal parasites. $P$ value $\leq 0.05$ at $95 \%$ Cl was considered statistically significant.

Results: The overall prevalence of intestinal parasites was 35.9\% (95\% Cl 31.0-40.9\%). Protozoa's (Entanmoeba histolytica/dispar trophozoite, E. histolytica/dispar cyst, Giardia lamblia trophozoite, and G. lamblia cyst), helminths (Tanea species, Ascaris lumbricoides, Strongyloid stercoralis, Hookworm species and H. nana), and opportunistic intestinal parasites (Cryptosporidium parvum, Isospora belli) were observed in 57 (17.1\%), 46 (14.4\%), and 28 (8.7\%) study participants respectively. Multivariate logistic regression analysis revealed that the presence of animals (AOR 6. 14; $95 \% \mathrm{Cl} 3.13$, 12.0); using river water (AOR 4.87; 95\% Cl 1.14, 20.7); undernutrition (AOR 2.59; 95\% Cl 1.36-4.95); and level of immunosuppression (AOR 4.02; 95\% Cl 1.78-9.05 and AOR 2.84; 95\% Cl 1.37-5.89) were significantly associated with intestinal parasites.

\footnotetext{
* Correspondence: drakselina@yahoo.com

'Department of Public Health, College of Medicine and Health Sciences,

Debre Markos University, Debre Markos, Ethiopia

Full list of author information is available at the end of the article
} 
(Continued from previous page)

Conclusions: The prevalence of intestinal parasites found to be higher among HIV/AIDS patients receiving HAART at Butajira Hospital, southern Ethiopia. Presence of animals, using river water, lower CD4 T cell count, and undernutrition were significant factors affecting intestinal parasites. Therefore, consistent detection of intestinal parasites and deworming of patients should be performed as well as improving health education on personal hygiene, avoiding contact with pit or domestic animals, and using safe or treated water. Furthermore, improving nutritional support and household food access are recommended.

Keywords: Intestinal parasites, HIV/AIDS, CD4, Undernutrition,

\section{Introduction}

Intestinal parasitic infections have been documented as one of the most significant causes of illnesses and diseases especially among resource limited setting. Globally, over three billion people were infected with one or more intestinal parasites [1]. However, it is a prevalent infectious disease in third world countries where there are socioeconomically poor communities, poor environmental sanitation, overcrowding, and inadequate access to safe water [2,3]. Intestinal parasites cause high morbidity and mortality of individuals, particularly sub-Saharan countries, and they have been associated with low educational performance, stunting, and physical weakness $[4,5]$. Moreover, intestinal parasites are highly related to the spread and progression of human immune deficiency virus/acquired immune deficiency syndrome (HIV/ AIDS) $[6,7]$.

HIV/AIDS and intestinal parasitic infections are linked in a viscous circle [8]. Intestinal parasitic infections, mainly helminths, cause chronic immune activation and twisting the immune response toward $\mathrm{T}$ helper- $2 \mathrm{im}$ mune responses [8-10]. Moreover, they also increase HIV infection and AIDS progression [11-13]. On the other hand, HIV by itself enhances the significance of intestinal parasitic infections; as the progression of AIDS, the risk of opportunistic parasites and diarrhea significantly increased [14-16].

The magnitude of intestinal parasites has been documented higher in different countries of developing countries, particularly in sub-Saharan Africa. Likewise, intestinal parasites are highly distributed in different parts of Ethiopia. Low level of environmental and personal hygiene, unsafe drinking water and food, and improper disposal of human excreta were reported as determinant factors associated with intestinal parasitic infections $[17,18]$.

There are different reports that showed high magnitude of intestinal parasites among people living with HIV/AIDS (PLWHA) in Ethiopia. Among common intestinal parasites, E. histolytica, G. lamblia, A. lumbricoides, $S$. stercoralis were reported frequently in different studies [19-22]. Similarly, opportunistic parasitic infections such as C. parvum, I. belli, and blastocystis were common feature in HIV/AIDS infections [22, 23].
Intestinal parasitic infection is one of the major causes of morbidity, and it is highly prevalent among PLWHA in different parts of Ethiopia. However, the burden of both common and opportunistic intestinal parasites among HIV/AIDS patients receiving HAART is not well studied in the study area. Furthermore, determinant factors affecting intestinal parasites, especially malnutrition and cluster differentiation (CD4) $\mathrm{T}$ cell count were not comprehensively assessed in relation to intestinal parasites. Therefore, the aim of this study was to determine the prevalence of intestinal parasites and associated risk factors among HIV/AIDS patients on HAART in Butajira, Ethiopia.

\section{Methodology \\ Materials and method Study design, period, and area}

An institution-based cross-sectional study was conducted at Butajira Hospital, Gurage Zone, Southern Nations, Nationalities, and People's Region (SNNPR), Ethiopia, between September 2015 and May 2016. Butajira hospital is found at Butajira town, which is a generalized hospital with 110 beds that gives health care for resident of Butajira and surrounding area. The town lies in the average at $2100 \mathrm{~m}$ above sea level and somewhat has warm climate. The hospital catchment area populations are estimated around 1.3 million. A total of 1110 HIV/AIDS patients have been registered to ART care clinic at Butajira Hospital, of which 450 were in preART care, and 660 were receiving HAART.

Operational definition Undernutrition: the study participants whose body mass index less than $18.50 \mathrm{~kg} / \mathrm{m}^{2}$ based on WHO classification for malnutrition using body mass index [24].

Household food insecurity access scale is a measure of household food insecurity of study subjects in the past 4 weeks. It was calculated based on Food and Nutrition Technical Assistance standardized tools. Then, it was classified into Food Secure, Mildly Food Insecure Access, Moderately Food Insecure Access, and Severely Food Insecure Access [25]. 
Household dietary diversity is the patient's economic ability to access a diversity of foods during the past 1 day ( $24 \mathrm{~h}$.). Twelve of the questions were used to assess dietary diversity based on Food and Agriculture Organization standardized tools. Then, the mean dietary diversity score in the study participants was computed. Finally, the tertiles of the dietary diversity score were calculated with the highest tertile categorized as adequate food diversity, while the lowest tertiles were inadequate food diversity [26].

Anemia status was classified by using the level of hemoglobin concentration in grams per deciliter based on WHO classifications. Hemoglobin level was ranged between 12 and $16 \mathrm{~g} / \mathrm{dl}$, and 13-17 g/dl was considered as normal for female and male patients respectively. The study participants were classified as anemic for male and female when the hemoglobin concentration was $<13$ and $<12 \mathrm{~g} /$ dl respectively [27].

Drug adherence status was estimated by percent of missed dose for the last 6 months. It was extracted from patients' chart combined with self-reported adherence measurement technique. Then classified based on WHO classifications into $1=$ Good adherence: if the average adherence is greater than $95 \%$ (patients missed $<2$ doses of 30 doses or $<3$ doses of 60 doses); $2=$ Fair adherence: if the average adherence is $85-94 \%$ (patients missed 3-5 doses of 30 doses or 3-9 doses of 60 doses); $3=$ Poor adherence: if the average adherence is $<85 \%$ (patients missed $>6$ doses from 30 doses or $>9$ doses of 60 doses) [28].

Level of immunosuppression was determined by $\mathrm{CD} 4 \mathrm{~T}$ cells level based on WHO classifications. Then, categorized into severe, moderate, mild, and not significant immunosuppression if patients' CD 4 T cells level were $<200$, $200-349,350-500$, and $>500 / \mathrm{mm}^{3}$ respectively [29].

\section{Sample size and sampling technique}

The sample size was determined using single population proportion formula taking prevalence of intestinal parasites among PLWHA receiving HAART in Addis Ababa, Ethiopia, (27.8\%) [30] with 5\% marginal error and 95\% confidence interval $(\mathrm{CI})$ of certainty (alpha $=0.05)$. In this study, $5 \%$ of the non-response rate was taken, and the final sample size was 323 . Therefore, 323 study participants were included in the study.

A systematic random sampling technique was used to select the study subjects. A systematic random sampling technique was used considering Butajira hospital ART clinic gave the service on the average 15 patients per day, and 660 patients were expected to visit the hospital in 3 months of data collection period. Since the sample size was 323, the sampling interval was determined two. From the first two subjects, one patient was randomly selected by lottery method, so every other patient was selected to participate in the study.

\section{Study populations and data collection}

The study populations were all adult PLWHA who were currently receiving HAART. Patients who were receiving HAART and involved in ART follow up clinic at Butajira hospital and aged 18 years and above were included in the study.

The data was collected from April to June 2016 using a structured questionnaire. Socio-demographic characteristics, nutrition, clinical-related characteristics, and laboratory data were collected. Two clinical nurses and two laboratory technicians were recruited and 2 days training was given. The data collection process was followed daily by the principal investigator. Data on opportunistic disease in the past 6 months, WHO clinical stages of disease, drug adherence and chronic diseases were obtained from patient charts. The CD4+ T cell count was measured by BD FACS calibur machine (US) and categorized according to its clinical significance. Hemoglobin was measured with CELL-DYN hematology analyzer (US).

\section{Stool sample collection and processing}

Appropriate amount of fresh stool sample was taken and processed at parasitology laboratory, Butajira hospital using standard procedure. In the case of formol-ether concentration method, about $1 \mathrm{~g}$ of stool sample was mixed with $7 \mathrm{ml}$ formalin saline in a clear $15-\mathrm{ml}$ conical centrifuge tube. Suspension was filtered through a sieve into second conical tube. After pouring $3 \mathrm{ml}$ of diethyl ether into the content and centrifuged for $5 \mathrm{~min}$ at medium speed, approximately $2500 \mathrm{rpm}$. The supernatant was discarded by tilting the tube and pour off all the fluid. The sediment mixed with the remaining small fluid and about two drops of the deposit was placed on a slide, to which a drop of iodine solution was added and covered with cover slide. The supernatant was poured away and the tube was replaced in its track. Finally, smear was prepared from the sediment and observed under light microscope with a magnification of $\times 100$ and $\times 400[31]$. In the case of modified Ziehl-Neelsen staining method, a portion of stool sample was processed for detection of C. parvum and I. belli. Briefly, thin smear was prepared directly from sediment of concentrated stool then allowed to air dry and flamed for a few seconds for sterilization. The slide was exposed with methanol for $5 \mathrm{~min}$ and stained with carbol fuchsine for $30 \mathrm{~min}$. The slide was washed with tap water and decolorized with $5 \%$ sulfuric acid for 1-3 min. The slide was then rinsed in tap water and observed under light microscope with a magnification of $\times 1000$ [31].

\section{Quality control}

The questionnaire was adapted and modified in our context from previous literatures. It was first prepared in English and then translated into the local language, Amharic, and 
then retranslated back to English by an expert to maintain its consistency. Training was given for data collectors and supervisor. Pre-testing of the questionnaire was conducted on 20 patients receiving ART in the nearby health center 3 weeks prior to the actual survey. The data collection process was strictly followed day to day by the supervisor and principal investigator. Aseptic techniques and standard operating procedures were followed during sample collection, processing, transportation, and identification of intestinal parasites and measuring blood samples.

\section{Data analysis and interpretation}

The data was checked for completeness, coded, and first entered into EPI-info version 7, then it was rechecked and transferred to the Statistical Package for Social Science (SPSS) version 20 for analysis. Chisquare was used to carry out a descriptive analysis. To assess the effect of the various factors related to intestinal parasites, bivariate and multivariate logistic regression analyses were used. The absence of multico-linearity was checked by using VIF/tolerance. The model adequacy was checked by using Hosmer and Lemeshow goodness of fit test. $P$ value $\leq 0.05$ at $95 \%$ CI was considered statistically significant.

\section{Results}

\section{Socio-demographic characteristics of the study participants}

A total of $323 \mathrm{HIV}$ infected participants on HAART were included in this study. The age of participants ranges from 22 to 78 years with a median of 39 years. More than three fifth of participants (61.5\%) were in the age group of $30-44$ years and $26.9 \%$ were above 44 years. The majority of the study participants (63.2\%) were women, and $50.8 \%$ of participants were married. Most of the participants $(86.4 \%)$ had low monthly income and $58.5 \%$ were urban dweller. Sixty-two (19.2\%) participants were daily laborers as shown in (Table 1).

\section{Environmental, clinical, and nutritional profiles of the study participants}

Most of the study participants (95.7\%) have a toilet in site their home, and 23.2\% participants had domestic (pit) animals. Twenty two (6.8\%) participants used river water as a source of water for basic activities. Fifty-four (16.7\%) of individuals had one or more gastrointestinal symptoms, of which diarrhea (8.7\%) was the highest rank followed by mal-digestion (8.0\%). The median CD4+ T cell count and hemoglobin concentration level of participants were 403 cells/ $\mu \mathrm{l}$ with 326 inter quartile range (IQR) and $13.1 \mathrm{~g} / \mathrm{dl}$ with $6 \mathrm{IQR}$ respectively. More than three fifth of participants were at WHO clinical stage one, and $36.2 \%$ of participants have their CD4 $\mathrm{T}$ cells count greater than 500 cells $/ \mu$ l. Eighty-eight (27.2\%) participants were anemic;
Table 1 Socio-demographic characteristics of the study subjects at Butajira Hospital, southern Ethiopia, 2014, $(n=323)$

\begin{tabular}{|c|c|c|}
\hline Characteristics & Frequency $(n)$ & Percent (\%) \\
\hline \multicolumn{3}{|l|}{ Sex } \\
\hline Male & 119 & 36.8 \\
\hline Female & 204 & 63.2 \\
\hline \multicolumn{3}{|l|}{ Age (years) } \\
\hline $18-29$ & 37 & 11.5 \\
\hline $30-44$ & 199 & 61.5 \\
\hline$\geq 45$ & 87 & 26.9 \\
\hline \multicolumn{3}{|l|}{ Residence } \\
\hline Urban & 189 & 58.5 \\
\hline Rural & 134 & 41.5 \\
\hline \multicolumn{3}{|l|}{ Marital status } \\
\hline Single & 19 & 5.9 \\
\hline Married & 164 & 50.8 \\
\hline Divorced & 44 & 13.6 \\
\hline Widowed & 86 & 26.6 \\
\hline Separated & 10 & 3.1 \\
\hline \multicolumn{3}{|l|}{ Educational status } \\
\hline Can read and write & 129 & 39.9 \\
\hline Cannot read and write & 39 & 12.1 \\
\hline Primary education & 86 & 26.6 \\
\hline Secondary education & 49 & 15.2 \\
\hline Tertiary education & 20 & 6.2 \\
\hline \multicolumn{3}{|l|}{ Religion } \\
\hline Orthodox & 153 & 47.4 \\
\hline Muslim & 106 & 32.8 \\
\hline Protestant & 62 & 19.2 \\
\hline Catholic & 2 & 0.6 \\
\hline \multicolumn{3}{|l|}{ Ethnicity } \\
\hline Gurage & 192 & 59.4 \\
\hline Silitie & 56 & 17.3 \\
\hline Amhara & 43 & 13.3 \\
\hline Oromo & 14 & 4.3 \\
\hline Hadiya & 17 & 5.3 \\
\hline \multicolumn{3}{|l|}{ Occupation } \\
\hline Governmental employer & 41 & 12.7 \\
\hline Self-employer & 55 & 17.0 \\
\hline Farmer & 42 & 13.0 \\
\hline Merchant & 50 & 15.5 \\
\hline Daily laborer & 62 & 19.2 \\
\hline House wife & 51 & 15.8 \\
\hline Jobless & 22 & 6.8 \\
\hline \multicolumn{3}{|l|}{ Monthly income (ETB) } \\
\hline$<1000$ & 279 & 86.4 \\
\hline
\end{tabular}


Table 1 Socio-demographic characteristics of the study subjects at Butajira Hospital, southern Ethiopia, 2014, $(n=323)$ (Continued)

\begin{tabular}{lll}
\hline$\geq 1000$ & 44 & 13.6 \\
Family size & & \\
$\leq 3$ & 156 & 48.3 \\
$4-6$ & 146 & 45.2 \\
$>6$ & 21 & 6.5 \\
\hline
\end{tabular}

however, most of them (91\%) were with good drug adherence. About $55.4 \%$ of participants were initiated with HAART care more than 3 years prior to data collection period (Table 2).

Regarding nutritional status of the study participants, the overall prevalence of undernutrition among PLWHA on HAART was $25.4 \%$. Mild, moderate, and severe malnutrition was observed in $15.8,196.5$, and $3.1 \%$ participants respectively. The majority of participants $(78.8 \%)$ were food insecure, of which 5.0, 32.2, and $41.8 \%$ were mildly, moderately, and severely food insecure respectively. Moreover, about 128 (39.7\%) individuals were with inadequate dietary diversity (Table 2 ).

\section{Prevalence of intestinal parasites among the study participants}

The overall prevalence of intestinal parasites among HIV/ AIDS patients receiving HAART was $35.9 \%$ (95\% CI 31.0-40.9\%). Protozoas, helminths, and opportunistic intestinal parasites were observed in 57 (17.1\%), 46 (14.4\%), and $28(8.7 \%)$ participants respectively. The most prevalent protozoan parasites, helminths, and opportunistic intestinal parasites among HIV/AIDS patients were $E$. histolytica/dispar trophozoite (7.1\%), Tanea species (7.4\%), and C. parvum (5.9\%) respectively. Infected participants were also found to harbor multiple types of parasites. Multiple parasitic infections were observed in $1.5 \%$ of the total examined patients (Table 3 ).

\section{Intestinal parasites and possible risk factors}

All the study variables computed by bivariate analysis were also investigated using multivariate analysis. In multivariate stepwise logistic regression analysis, out of nine selected variables in bivariate analyses, only four variables (presence of animals, source of water, CD4 T cell count, and undernutrition) were retained and significantly associated with intestinal parasites. The remaining five variables (age, educational status, income, presence of toilet, WHO clinical stages) were failed to associate significantly with intestinal parasites in the multivariate model (Table 4).

In this study, the presence of one or more animals in the house were significantly associated with intestinal parasites $(P=0.00)$. Participants who had one or more
Table 2 Environmental, clinical, and nutritional profiles of the study participants at Butajira Hospital, southern Ethiopia, 2014, $(n=323)$

\begin{tabular}{lll}
\hline Variables & Frequency $(n)$ & Percent (\%) \\
\hline Presence of animals & & \\
No & 248 & 76.8 \\
Yes & 75 & 23.2 \\
Presence of toilet & & \\
No & 14 & 4.3 \\
Yes & 309 & 95.7 \\
Source of water & & \\
Tape & 301 & 93.2 \\
River & 22 & 6.8
\end{tabular}

Eating difficulty

$\mathrm{No}$

Yes

Loss of appetite

Vomiting

Nausea

Swallowing difficulty

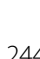

75.5

24.5

21.7

7.1

4.3

1.9

Gastrointestinal symptoms

No

83.3

Yes

Diarrhea

Indigestion

Constipation

WHO clinical stage

Stage I

60.7

Stage \|

18.0

Stage III

19.2

Stage IV

CD4+ T cell count (cells/ $\mu \mathrm{l})$

$$
<200
$$

16.4

200-349

Anemia status

Normal

72.8

Anemic

Current/past $\mathrm{OI}$ in the past 6 months

No

58.5

Yes

41.5

Duration of HAART

$\begin{array}{ll}<6 \text { months } & 40 \\ 6-12 \text { months } & 48 \\ 1-3 \text { years } & 56\end{array}$

12.4

14.9

17.3 
Table 2 Environmental, clinical, and nutritional profiles of the study participants at Butajira Hospital, southern Ethiopia, 2014, $(n=323)$ (Continued)

\begin{tabular}{lll}
\hline$>3$ years & 179 & 55.4 \\
$\begin{array}{l}\text { Drug adherence } \\
\text { Good }\end{array}$ & 294 & 91.0 \\
Fair & 21 & 6.5 \\
Poor & 8 & 2.5 \\
Nutritional status & & \\
Severe malnourished & 10 & 3.1 \\
Moderate malnourished & 21 & 6.5 \\
Mild malnourished & 51 & 15.8 \\
Nourished & 201 & 62.2 \\
Over weight and obese & 40 & 12.4 \\
Household food insecurity status & & \\
Food secured & 68 & 21.1 \\
Mildly food in secured & 16 & 5.0 \\
Moderately food in secured & 104 & 32.2 \\
Severely food in secured & 135 & 41.8 \\
Household dietary diversity & & 39.6 \\
Inadequate & 128 & 60.4 \\
Adequate & 195 & \\
\hline
\end{tabular}

animals in their house were six times more likely to be infected with one or more intestinal parasites as compared with those free animals in their home (AOR 6.14; $95 \%$ CI 3.13, 12.0). Using river water was also significantly associated with intestinal parasites $(P=0.03)$. Participants whose source of drinking water were river water were four times more likely to be infected with one or more intestinal parasites as compared with those using tap water (AOR 4.87; 95\% CI 1.14, 20.7). Intriguingly, CD4 $\mathrm{T}$ cell lymphocyte was highly associated with intestinal parasites $(P=0.00)$. Immunocompromised patients whose CD4 T cell lymphocytes less than 200 and 200-349 cells/ $\mu$ l were more likely to be infected with one or more intestinal parasites as compared to those who had above 500 cells/ $\mu \mathrm{l}$, (AOR 4.02; 95\% CI 1.78-9.05) and (AOR 2.84; 95\% CI 1.37-5.89) respectively. Moreover, undernutrition were significantly associated with intestinal parasites $(P=0.004)$. Under-nourished patients were 2.59 times more likely to be infected in one or more intestinal parasites as compared with nourished individuals (AOR 2.59; 95\% CI 1.36-4.95).

\section{Discussion}

This study revealed the prevalence of intestinal parasites and associated risk factors among HIV/AIDS patients receiving HAART at Butajira Generalized Hospital. The overall prevalence $(35.9 \%)$ of intestinal parasites among
Table 3 Intestinal parasites co-infection among the study participants at Butajira Hospital, southern Ethiopia, 2014, $(n=323)$

\begin{tabular}{lll}
\hline Intestinal parasites & $\begin{array}{l}\text { Frequency } \\
(n)\end{array}$ & $\begin{array}{l}\text { Percent } \\
(\%)\end{array}$ \\
\hline Negative & 207 & 64.1 \\
Positive & 116 & 35.9 \\
Protozoas & & \\
$\quad$ E. histolytica/dispar trophozoite & 23 & 7.1 \\
E. histolytica/dispar cyst & 15 & 4.6 \\
G. lamblia trophozoite & 17 & 4.8 \\
G. lamblia cyst & 2 & 0.6 \\
Helminthes & & \\
Tanea species & 24 & 7.4 \\
A. lumbricoides & 10 & 3.1 \\
S. stercoralis & 5 & 1.5 \\
Hookworm species & 2 & 0.7 \\
H. nana & 5 & 1.5 \\
Opportunistic parasites & & \\
C. parvum & & \\
I. belli & 19 & 5.9 \\
Multiple parasitic infections & 9 & 2.8 \\
E. histolytica/dispar trophozoite + G. lamblia & 2 & 0.6 \\
trophozoite & & \\
E. histolytica/dispar trophozoite + A. & 2 & \\
lumbricoides & & \\
G. lamblia trophozoite + Tanea species & 1 & \\
\hline & & \\
\hline
\end{tabular}

PLWHA receiving HAART remains significant. This finding was relatively higher than previous studies conducted in France (22\%), Brazil (14\%), Nepal (22.4\%), Congo (8.5\%), Cameron (24.6\%), and Nigeria (15.3\%) [32-37]. However, the result of this study was lower than a study conducted in Iran (67.7\%) and in different countries of Ethiopia including in selected ART clinic Adama, Afar, Dire-Dawa (48\%), and Bahirdar (69\%) [22, 38, 39]. On the other hand, Telele et al. and Missaye et al. also reported 24.3 and $17.3 \%$ prevalence of intestinal parasites in Gondar and Dessie, Ethiopia, respectively [22, 40]. The discrepancy of the prevalence among different parts of the country may reflect the existence of diverse ethnic experiences and implementing prevention and treatment measures against intestinal parasites. Furthermore, it is wise to expect the existence of variation in geographic location and general hygiene of the population.

In the current study, we found that the presence of one or more animals in the house was significantly associated with intestinal parasites $(P=0.00)$. Participants who had one or more animals in their house were six times more likely to be infected with one or more intestinal parasites as compared to those who had no animals. This finding was in accordance with Mohan et al. 
Table 4 Risk factors associated with intestinal parasites among PLWHA receiving HAART at Butajira Hospital, southern Ethiopia, 2014, $(n=323)$

\begin{tabular}{|c|c|c|c|c|c|}
\hline \multirow[t]{2}{*}{ Predictors } & \multicolumn{2}{|c|}{ Intestinal parasites } & \multirow[t]{2}{*}{ COR $(95 \% \mathrm{Cl})$} & \multirow[t]{2}{*}{ AOR $(95 \% \mathrm{Cl})$} & \multirow[t]{2}{*}{$P$ values } \\
\hline & Yes & No & & & \\
\hline \multicolumn{6}{|l|}{ Residence } \\
\hline Urban & 62 & 127 & 1 & & \\
\hline Rural & 80 & 54 & $1.38(0.87-2.19)$ & & \\
\hline \multicolumn{6}{|l|}{ Educational status } \\
\hline Unable to read and write & 55 & 74 & $4.21(1.17-15.0)$ & & \\
\hline Able to read and write & 14 & 25 & $3.17(0.79-12.7)$ & & \\
\hline Primary education & 23 & 63 & $2.06(0.55-7.72)$ & & \\
\hline Secondary education & 28 & 21 & $4.25(1.10-16.4)$ & & \\
\hline Tertiary education & 3 & 17 & 1 & & \\
\hline \multicolumn{6}{|l|}{ Income (ETB) } \\
\hline$<1000$ & 107 & 172 & $2.42(1.12-5.23)$ & & \\
\hline$\geq 1000$ & 9 & 35 & 1 & & \\
\hline \multicolumn{6}{|l|}{ Presence of animal } \\
\hline Yes & 51 & 24 & $5.98(3.41-10.5)$ & $6.14(3.13-12.0)$ & $0.00^{* *}$ \\
\hline No & 65 & 183 & 1 & 1 & \\
\hline \multicolumn{6}{|l|}{ Presence of toilet } \\
\hline Yes & 103 & 206 & 1 & & \\
\hline No & 13 & 1 & $26(3.3-201)$ & & \\
\hline \multicolumn{6}{|l|}{ Source of water } \\
\hline Tape & 98 & 203 & 1 & 1 & \\
\hline River & 18 & 4 & $9.32(3.07-28.3)$ & $4.87(1.14-20.7)$ & $0.03^{*}$ \\
\hline \multicolumn{6}{|l|}{ WHO stages } \\
\hline Stage I & 66 & 130 & 1 & & \\
\hline Stage II & 30 & 28 & $2.11(1.16-3.82)$ & & \\
\hline Stage III & 18 & 44 & $0.81(0.43-1.50)$ & & \\
\hline Stage IV & 2 & 5 & $0.78(0.15-4.17)$ & & \\
\hline CD4 T cell count & & & & & $0.00^{* *}$ \\
\hline$<200$ & 31 & 22 & $3.74(1.89-7.39)$ & $4.02(1.78-9.05)$ & \\
\hline 200-349 & 33 & 41 & $2.13(1.16-3.94)$ & $2.84(1.37-5.89)$ & \\
\hline $350-500$ & 20 & 59 & $0.90(0.47-1.72)$ & $1.01(0.46-2.20)$ & \\
\hline$>500$ & 32 & 85 & 1 & 1 & \\
\hline \multicolumn{6}{|l|}{ Undernutrition } \\
\hline Yes & 44 & 38 & $2.72(1.62-4.54)$ & $2.59(1.36-4.95)$ & $0.004^{*}$ \\
\hline No & 72 & 169 & 1 & 1 & \\
\hline
\end{tabular}

Stepwise (Backward LR) was used in logistic regression. Hosmer and Lemeshow test was at $P=0.31$

N.B $a=0.05$

*Significant, **Highly significant

[41] and Dwivedi et al. [42]. The association might be due to living of human with domestic animals which increases a tendency to contact with pit or domestic animal excretion and consuming their products. So, those patients will be more vulnerable to be infected with one or more intestinal parasites [43, 44]. C. parvum and giardia are ubiquitous parasites in mammals, particularly domestic animals and those protozoan were commonly identified in dogs, sheep, and horses [45-47].

Participants whose source of water were river water were four times more likely to be infected with one or more intestinal parasites as compared to those using tap water $(P=0.03)$. Similar results were found in studies conducted in Nigeria, Malaysia, and Ethiopia [20, 48, 49]. In 
fact, river/unprotected water is highly contaminated with animals and human excretion since people are usually bathing and washing their clothes under river. These habits have been practiced in developing countries particularly in Ethiopia due to scarcity or inadequate distribution of safe/clean water. So, using untreated/unsafe water contributes to be infected with one or more intestinal parasitic infections $[50,51]$. The most prevalent waterborne intestinal parasites producing diarrhea are cryptosporidiosis, giardiasis, and E. histolytica. These parasitic infections have been commonly reported in immunocompromised patients, particularly in HIV/AIDS patients [51].

The other pertinent finding was CD4 T cell count which was highly associated with intestinal parasites $(P$ $=0.00$ ). Immunocompromised patients whose CD4 T cells below 350 cells/ $\mu$ l were more likely to be infected with a particular intestinal parasite. This is in agreement with previous findings in Nigeria [37], Nepal [34], and different parts of Ethiopia like Addis Ababa [30], Hawasa [16], and Dessie [20]. The reduction in CD4 T cell count in PLWHA predisposes to intestinal parasites, especially opportunistic intestinal parasitic infections [52-54]. Immuno-deficient patients are more susceptible to acquiring intestinal parasites, and they are unable to clear once infection is established [55].

Moreover, undernutrition was significantly associated with intestinal parasites $(P=0.004)$. Participants who were under-nourished 2.59 times more likely to be infected with one or more intestinal parasites as compared to nourished individual. Infectious diseases and malnutrition have interconnected one another in a viscous cycle. Malnourished individuals are more vulnerable to be infected with a particular intestinal parasite as compared to nourished individuals because malnourished individuals lead to decreased immune function, mucosal damage, and increased invasion by intestinal parasites. Furthermore, malabsorption, loss of appetite, and diarrhea, all of which, lead to nutrient losses and further damage to defense mechanisms $[56,57]$.

The limitation of the current study could be other laboratory technique like water-ether sedimentation method which was not used for detection of microsporidia. In addition, we have not used molecular techniques and immune-fluorescent techniques sensitive for parasites. Besides, assessment of household dietary diversity and household food insecurity status depends on the past 24-h and 1-month period recall method, respectively, which might create a possibility of recall bias.

\section{Conclusions}

The prevalence of intestinal parasites found to be higher among HIV/AIDS patients receiving HAART at Butajira Hospital, southern Ethiopia. Presence of animals, using river water, lower $\mathrm{CD} 4 \mathrm{~T}$ Cell count, and undernutrition were significant factors affecting intestinal parasites. Routine and consistent detection of intestinal parasites should be performed. Moreover, improving public health measures that should emphasize on personal hygiene, avoiding contact with pit or domestic animals, using safe or treated water, and improving nutritional support and household food access are recommended.

\begin{abstract}
Abbreviations
AIDS: Acquired immunodeficiency syndrome; AOR: Adjusted odds ratio; BD FACS: Becton Dickson fluorescent activated cell sorter; CD: Cluster of differentiation; HAART: Highly active anti-retroviral therapy; HIV: Human immunodeficiency virus; PLWHA: People living with HIV/AIDS;

SNNPR: Southern Nations, Nationalities, and People's Region; SPSS: Statistical package for social science; WHO: World Health Organization
\end{abstract}

\section{Acknowledgements}

We would like to thank Mr. Daregaze Kibru and Zenebe Gedle for providing us the reagents/materials/analysis tools during data collection and laboratory investigation.

\section{Funding}

This study was supported by University of Gondar for the data collection material and reagents. However, it had no role in the study design, analysis, decision to publish, or preparation of the manuscript.

\section{Availability of data and materials}

The datasets supporting the conclusions of this article are included within the article and its additional files.

For further queries, the datasets used and/or analyzed during the current study are also available from the corresponding author on reasonable request.

\section{Authors' contributions}

DG conceived and designed the study, wrote the paper, conducted the data analysis, and drafted and finalized the manuscript for publication. GK, FF, TE, $\mathrm{KK}$, and $\mathrm{HA}$ assisted with the data collection and critical reviewing of the papers. All authors read and approved the final manuscript.

\section{Competing interests}

The authors declare that they have no competing interests.

\section{Consent for publication}

Not applicable

\section{Ethics approval and consent to participate}

Ethical approval was obtained from an ethical review committee of the School of Biomedical and Laboratory Sciences, College of Medicine and Health Sciences, University of Gondar prior to data collection. Permission was taken from Butajira Zonal Hospital administrators, and written informed consent was obtained from each individual after the purpose of the study was explained. Participants were told that they had full right to participate or not, and they were also informed that all the data obtained from them would be kept confidential using codes instead of any personal identifiers. In addition, we have received finger print signature from illiterate participants after explaining the purpose of the study. The study participants who were positive for intestinal parasites and anemic were referred to ART clinicians for treatment. In addition, those participants identified as undernutrition were given nutritional counseling and Ready Use Therapeutic Food in

collaboration with the clinicians working in an ART clinic at Butajira Hospital.

\section{Publisher's Note}

Springer Nature remains neutral with regard to jurisdictional claims in published maps and institutional affiliations.

\section{Author details}

'Department of Public Health, College of Medicine and Health Sciences, Debre Markos University, Debre Markos, Ethiopia. ${ }^{2}$ Department of midwifery, College of Medicine and Health Sciences, Debre Markos University, Debre 
Markos, Ethiopia. ${ }^{3}$ Department of Nursing, College of Medicine and Health Sciences, Debre Markos University, Debre Markos, Ethiopia.

\section{Received: 14 December 2016 Accepted: 5 May 2017 Published online: 15 May 2017}

\section{References}

1. WHO. Sustaining the drive to overcome the global impact of neglected tropical diseases: second WHO report on neglected diseases: World Health Organization; 2013

2. Mehraj V, Hatcher J, Akhtar S, Rafique G, Beg MA. Prevalence and factors associated with intestinal parasitic infection among children in an urban slum of Karachi. PLoS One. 2008;3(11):e3680.

3. Ngui R, Ishak S, Chuen CS, Mahmud R, Lim YA. Prevalence and risk factors of intestinal parasitism in rural and remote West Malaysia. 2011.

4. Nokes C, Bundy D. Does helminth infection affect mental processing and educational achievement? Parasitol Today. 1994;10(1):14-8.

5. Nokes C, Grantham-McGregor S, Sawyer A, Cooper E, Bundy D. Parasitic helminth infection and cognitive function in school children. Proc R Soc Lond B Biol Sci. 1992:247(1319):77-81.

6. Bentwich Z, Kalinkovich A, Weisman Z. Immune activation is a dominant factor in the pathogenesis of African AIDS. Immunol Today. 1995;16(4):187-91.

7. Oteng-Seifah EE. The prevalence of intestinal parasitic infection and their association with the t-cell cd4+ counts of hiv/aids infected patients in Kumasi. 2015

8. Grossman Z, Meier-Schellersheim M, Sousa AE, Victorino RM, Paul WE. CD4+ T-cell depletion in HIV infection: are we closer to understanding the cause? Nat Med. 2002;8(4):319-23.

9. Borkow G, Bentwich Z. Chronic immune activation associated with chronic helminthic and human immunodeficiency virus infections: role of hyporesponsiveness and anergy. Clin Microbiol Rev. 2004;17(4):1012-30.

10. MacDonald AS, Araujo MI, Pearce EJ. Immunology of parasitic helminth infections. Infect Immun. 2002;70(2):427-33.

11. Secor WE, Shah A, Mwinzi PM, Ndenga BA, Watta CO, Karanja DM. Increased density of human immunodeficiency virus type 1 coreceptors CCR5 and CXCR4 on the surfaces of CD4+ T cells and monocytes of patients with Schistosoma mansoni infection. Infect Immun. 2003;71(11):6668-71.

12. Kalinkovich A, Borkow G, Weisman Z, Tsimanis A, Stein M, Bentwich Z. Increased CCR5 and CXCR4 expression in Ethiopians living in Israel: environmental and constitutive factors. Clin Immunol. 2001;100(1):107-17.

13. Shapira-Nahor O, Kalinkovich A, Weisman Z, Greenberg Z, Nahmias J, Shapiro M, Panet A, Bentwich Z. Increased susceptibility to HIV-1 infection of peripheral blood mononuclear cells from chronically immune-activated individuals. AIDS (London, England). 1998:12(13):1731-3.

14. Gupta S, Narang S, Nunavath V, Singh S. Chronic diarrhoea in HIV patients: prevalence of coccidian parasites. Indian J Med Microbiol. 2008;26(2):172.

15. Kelly P, Todd J, Sianongo S, Mwansa J, Sinsungwe H, Katubulushi M, Farthing MJ, Feldman RA. Susceptibility to intestinal infection and diarrhoea in Zambian adults in relation to HIV status and CD4 count. BMC Gastroenterol. 2009:9(1):7.

16. Assefa S, Erko B, Medhin G, Assefa Z, Shimelis T. Intestinal parasitic infection in relation to HIV/AIDS status, diarrhea and CD4 T-cell count. BMC Infect Dis. 2009;9(1):155

17. Kumie A, Ali A. An overview of environmental health status in Ethiopia with particular emphasis to its organization, drinking water and sanitation: a literature survey. Ethiop J Health Dev. 2005;19(2):89.

18. Kelly P. Diarrhoea and AIDS: recent developments in the African setting. Afr Health. 1998;20(6):16-8

19. Gedle D, Gelaw B, Muluye D, Mesele M. Prevalence of malnutrition and Its associated factors among adult people living with HIV/AIDS receiving antiretroviral therapy at Butajira Hospital, Southern Ethiopia. BMC Nutr. 2015;1(1):5.

20. Missaye A, Dagnew M, Alemu A, Alemu A. Prevalence of intestinal parasites and associated risk factors among HIV/AIDS patients with pre-ART and onART attending dessie hospital ART clinic, Northeast Ethiopia. AIDS Res Ther. 2013;10(1):19.

21. Woldemichael T, Mohanned H. Diarrhoea-associated parasitic infectious agents in AIDS patients within selected Addis Ababa Hospitals. Bitew Fisseha, Beyene Petros. Ethiop J Health Devel. 1999:13(3):169-74.

22. Alemu A, Shiferaw Y, Getnet G, Yalew A, Addis Z. Opportunistic and other intestinal parasites among HIV/AIDS patients attending Gambi higher clinic in Bahir Dar city, North West Ethiopia. Asian Pac J Trop Med. 2011;4(8):661-5.
23. Shah U, Purohit B, Chandralekha D, Mapara M. Coinfection with Cryptosporidium, Isospora and S. stercoralis in a patient with aids-a case report. Indian J Med Microbiol. 2003;21(2):137.

24. WHO. Physical status: the use and interpretation of anthropometry. In: Series WTR, editor. Report of a WHO Expert Committee, vol. 85. 4th ed. Geneva: World Health Organization; 2004.

25. USAID. Household Food Insecurity Access Scale (HFIAS) for measurement of food access: indicator guide: United States Agency for International Development; 2007

26. FAO. Guidelines for measuring household and individual dietary diversity: Food and Agriculture Organization of the United Nations; 2011.

27. WHO. In: De Benoist B, McLean E, Egli I, Cogswell M, editors. Worldwide prevalence of anaemia 1993-2005 Who global database on anaemia. 2nd ed. Geneva: World Health Organization; 2008.

28. WHO. Antiretroviral therapy for HIV infection in adults and adolescents: recommendations for a public health approach. World Health Organization; 2006.

29. WHO. Interim WHO clinical staging of HVI/AIDS and HIV/AIDS case definitions for surveillance: African Region. World Health Organization; 2005.

30. Mengist HM, Taye B, Tsegaye A. Intestinal parasitosis in relation to CD4+ T cells levels and anemia among HAART initiated and HAART naive pediatric HIV patients in a model ART center in Addis Ababa, Ethiopia. PloS one. 2015;10(2):e0117715.

31. Cheesbrough M. Medical laboratory manual for tropical countries, Volume 1. 2nd edition. Cambridge press; 1992:208-210.

32. Pavie J, Menotti J, Porcher R, Donay JL, Gallien S, Sarfati C, Derouin F, Molina J-M. Prevalence of opportunistic intestinal parasitic infections among HIVinfected patients with low CD4 cells counts in France in the combination antiretroviral therapy era. Int J Infect Dis. 2012;16(9):e677-9.

33. Bachur TPR, Vale JM, Coêlho ICB, Queiroz TRBS, Chaves CS. Enteric parasitic infections in HIV/AIDS patients before and after the highly active antiretroviral therapy. Braz J Infect Dis. 2008;12(2):115-22.

34. Tiwari BR, Ghimire P, Malla S, Sharma B, Karki S. Intestinal parasitic infection among the HIV-infected patients in Nepal. J Infect Dev Ctries. 2013;7(07):550-5.

35. Wumba R, Longo-Mbenza B, Mandina M, Wobin TO, Biligui S, Sala J, Breton J, Thellier M. Intestinal parasites infections in hospitalized AIDS patients in Kinshasa, Democratic Republic of Congo. Parasite. 2010;17(4):321-8.

36. Sarfati C, Bourgeois A, Menotti J, Liégeois F, Moyou-Somo R, Delaporte E, Derouin F, Ngole EM, Molina J-M. Prevalence of intestinal parasites including microsporidia in human immunodeficiency virus-infected adults in Cameroon: a cross-sectional study. AmJTrop Med Hyg. 2006;74(1):162-4.

37. Akinbo FO, Okaka CE, Omoregie R. Prevalence of intestinal parasitic infections among HIV patients in Benin City, Nigeria. Libyan Journal of Medicine. 2010;5(1):5506.

38. Berenji F, Sarvghad MR, Fata A, Hosseininejad Z, Saremi E, Ganjbakhsh M, Jahanparvar RI. A study of the prevalence of intestinal parasitic infection in HIV positive individuals in Mashhad, Northeast Iran. Jundishapur J Microbiol. 2010;3(2):61-5.

39. Adamu H, Petros B. Intestinal protozoan infections among HIV positive persons with and without Antiretroviral Treatment (ART) in selected ART centers in Adama, Afar and Dire-Dawa, Ethiopia. Ethiopian Journal of Health Development. 2009;23(2):133-40.

40. Telele NF. Intestinal parasitic infections among hiv seropositive and seronegative adult patients presented with diarrhoea in Gondar, Northwest Ethiopia. Presented at the 4th INTEREST Workshop. 2010; 2010: 28.

41. Mylavarapu RM, Nagamani K, Saxena NK. Enteric parasites in HIV/AIDS patients: study of the prevalence and risk factors. Int J Biomed Res. 2013:4(8):377-80.

42. Dwivedi KK, Prasad G, Saini S, Mahajan S, Lal S, Baveja UK. Enteric opportunistic parasites among HIV infected individuals: associated risk factors and immune status. Jpn J Infect Dis. 2007:60(2/3):76.

43. Alyousefi NA, Mahdy MA, Mahmud R, Lim YA. Factors associated with high prevalence of intestinal protozoan infections among patients in Sana'a City, Yemen. PLoS One. 2011;6(7):e22044

44. Glaser CA, Angulo FJ, Rooney JA. Animal-associated opportunistic infections among persons infected with the human immunodeficiency virus. Clin Infect Dis. 1994:18(1):14-24.

45. Causape A, Quilez J, Sánchez-Acedo C, Del Cacho E. Prevalence of intestinal parasites, including Cryptosporidium parvum, in dogs in Zaragoza city, Spain. Vet Parasitol. 1996;67(3-4):161-7.

46. Casemore D. Sheep as a source of human cryptosporidiosis. J Infect. 1989; 19(2):101-4. 
47. Olson M, Thorlakson C, Deselliers L, Morck D, McAllister T. Giardia and Cryptosporidium in Canadian farm animals. Vet Parasitol. 1997;68(4):375-81.

48. Wokem G, Chukwu C, Nwachukwu C. Prevalence of intestinal parasites seen in HIV sero-positive subjects in Port Harcourt, Nigeria, Nigerian. J Parasitol. 2008;29(2):115-20.

49. Ngui R, Ishak S, Chuen CS, Mahmud R, Lim YA. Prevalence and risk factors of intestinal parasitism in rural and remote West Malaysia. PLoS Negl Trop Dis. 2011; 5(3):e974.

50. Slifko TR, Smith HV, Rose JB. Emerging parasite zoonoses associated with water and food. Int J Parasitol. 2000;30(12):1379-93.

51. Baldursson S, Karanis P. Waterborne transmission of protozoan parasites: review of worldwide outbreaks — an update 2004-2010. Water Res. 2011; 45(20):6603-14.

52. Wiwanitkit $\mathrm{V}$. Intestinal parasitic infections in Thai HIV-infected patients with different immunity status. BMC Gastroenterol. 2001;1(1):3.

53. Kurniawan A, Karyadi T, Dwintasari S, Sari I, Yunihastuti E, Djauzi S, Smith H. Intestinal parasitic infections in HIV/AIDS patients presenting with diarrhoea in Jakarta, Indonesia. Trans R Soc Trop Med Hyg. 2009;103(9):892-8.

54. Lee J-K, Song H-J, Yu J-R. Prevalence of diarrhea caused by Cryptosporidium parvum in non-HIV patients in Jeollanam-do, Korea. Korean J Parasitol. 2005; 43(3):111.

55. Evering $T$, Weiss $L$. The immunology of parasite infections in immunocompromised hosts. Parasite Immunol. 2006;28(11):549-65.

56. Katona $\mathrm{P}$, Katona-Apte J. The interaction between nutrition and infection. Clin Infect Dis. 2008;46(10):1582-8.

57. Hall A, Hewitt G, Tuffrey $\vee$, De Silva N. A review and meta-analysis of the impact of intestinal worms on child growth and nutrition. Matern Child Nutr. 2008;4(s1):118-236.

\section{Submit your next manuscript to BioMed Central and we will help you at every step:}

- We accept pre-submission inquiries

- Our selector tool helps you to find the most relevant journal

- We provide round the clock customer support

- Convenient online submission

- Thorough peer review

- Inclusion in PubMed and all major indexing services

- Maximum visibility for your research

Submit your manuscript at www.biomedcentral.com/submit 